\title{
Development of Design Technology on Thermal-Hydraulic Performance in Tight-Lattice Rod Bundles: II - Rod Bowing Effect on Boiling Transition under Transient Conditions*
}

\author{
Wei LIU**, Hidesada TAMAI**, Masatoshi KURETA**, \\ Akira OHNUKI** and Hajime AKIMOTO** \\ ** Japan Atomic Energy Agency (JAEA) \\ 2-4 Shirakata Shirane, Tokai, Ibaraki 319-1195, Japan \\ E-mail: liu.wei@jaea.go.jp
}

\begin{abstract}
A thermal-hydraulic feasibility project for an Innovative Water Reactor for Flexible fuel cycle (FLWR) has been performed since 2002. In this R\&D project, large-scale thermal-hydraulic tests, several model experiments and development of advanced numerical analysis codes have been carried out. In this paper, we describe the critical power characteristics in a 37-rod tight-lattice bundle with rod bowing under transient states. It is observed that transient Boiling Transition (BT) always occurs axially at exit elevation of upper high-heat-flux region and transversely in the central area of the bundle, which is same as that under steady state. For the postulated power increase and flow decrease cases that may be possibly met in a normal operation of the FLWR, it is confirmed that no BT occurs when Initial Critical Power Ratio (ICPR) is 1.3. Moreover, when the transients are run under severer $I C P R$ that causes BT, the transient critical powers are generally same as the steady ones. The experiments are analyzed with a modified TRAC-BFI code, where Japan Atomic Energy Agency (JAEA) newest critical power correlation is implemented for the BT judgement. The code shows good prediction for the occurrence or the non occurrence of the BT and predicts the BT starting time conservatively. Traditional quasi - steady state prediction of the transient BT is confirmed being applicable for the postulated abnormal transient processes in the tight-lattice bundle with rod bowing.
\end{abstract}

Key words: Critical Power, Transient, Rod Bowing, Boiling Transition, Tight Lattice Rod Bundle, FLWR

\section{Introduction}

A new reactor concept of Innovative Water Reactor for Flexible Fuel Cycle (FLWR) has been proposed by Japan Atomic Energy Agency (JAEA) ${ }^{(1)(2)}$. The FLWR is based on matured water-cooled reactor technology, but the core concept aims at an effective and flexible utilization of uranium and plutonium resources through plutonium multiple recycling. To meet the fuel recycle target of a high conversion ratio (greater than 1), axial blankets with depleted uranium are used with being arranged in a triangular tight-lattice bundle. To achieve a negative void reactivity coefficient, the core is designed to be short and flat to increase neutron leakage from the core. The core is characterized by a tightlattice arrangement, double-humped short flat core, low mass velocity and high in-core average void fraction $(70 \%)$. These new characteristics make the core cooling ability be

*Received 30 Aug., 2007 (No. 07-0434) [DOI: 10.1299/jpes.2.240] 
more severe. The confirmations to the core cooling ability and the establishments of proper evaluation methods for critical power under both steady and transient states are the most important R\&D items for the FLWR.

JAEA started the R\&D project to investigate thermal-hydraulic performance in tight-lattice rod bundles in collaboration with power companies, reactor suppliers and universities since 2002. Several critical power experiments using small-scale tight-lattice rod bundles have been carried out by JAEA ${ }^{(3)(4)}$ and Toshiba Corporation ${ }^{(5)(6)}$. These experiments obtained fundamental critical power and pressure drop data using tight-lattice 7-rod and 14-rod bundles. As the effects of cold walls are large in these small size bundles, experimental investigations on critical power in comparatively large rod bundles are inevitable for the design of the FLWR.

Under such background, critical power experiments using 37-rod bundle with rod gap of $1.3 \mathrm{~mm}$ were performed in FY 2003. The test bundle is called as "base case" bundle. In FY 2004, with the aim to confirm the effect of rod gap, tests were performed using a tighter rod-bundle with a rod gap of $1.0 \mathrm{~mm}$. The test bundle is called as "rod gap effect" bundle. With a further consideration to fuel rod deformation due to irradiation, water chemistry, etc., in FY 2005, tests were performed using 37-rod bundle with rod bowing. The test bundle is called as "rod bowing effect" bundle. The tests using 37-rod bundle so far performed are summarized in Table.1.

Table 1 Test items in large-scale thermal-hydraulic test

\begin{tabular}{c|c|ccc}
\hline \multicolumn{2}{c|}{$\begin{array}{c}\text { Type of } \\
\text { test section }\end{array}$} & $\begin{array}{c}\text { Base case } \\
(\text { Rod gap }=1.3 \mathrm{~mm})\end{array}$ & $\begin{array}{c}\text { Rod gap effect } \\
(\text { Rod gap }=1.0 \mathrm{~mm})\end{array}$ & $\begin{array}{c}\text { Rod bowing effect } \\
(\text { Rod gap }=1.3 \mathrm{~mm})\end{array}$ \\
\hline \multicolumn{2}{c}{ FY } & 2003 & 2004 & 2005 \\
\hline $\begin{array}{c}\text { Critical } \\
\text { Power }\end{array}$ & $\begin{array}{c}\text { Steady } \\
\text { state }\end{array}$ & $\begin{array}{c}\text { Transient } \\
\text { state }\end{array}$ & Parameter: flow rate, fluid temperature, pressure, local peaking \\
\hline \multicolumn{2}{l}{ Flow characteristics } & \multicolumn{3}{c}{ Parameter: flow decrease, power increase } \\
\hline
\end{tabular}

The fundamental critical power characteristics under steady state for the base case, the rod gap effect case and the rod bowing effect case have been reported already ${ }^{(7)(8)(9)}$. For the critical power characteristics under transient conditions, Liu et al. ${ }^{(10)}$ have reported that the critical powers under the postulated transient processes that may be possibly met in the normal operation of the FLWR, can be treated as quasi-steady state for the base case and the rod gap effect case, as that in the conventional BWR core. In this paper, the characteristics of the transient critical power measured in the rod bowing effect test will be described. The aim of the research is to ascertain the Boiling Transition (BT) characteristics under the postulated transient processes in the tight-lattice rod bundle with a rod bowing. In other words, weather the transient BT in the rod bowing effect case can be treated as quasi-steady state as that in the conventional BWR or not.

\section{Nomenclature}

$F_{\mathrm{r}}$ : radial power peaking factor, [-]

$G$ : mass velocity, $\left[\mathrm{kg} /\left(\mathrm{m}^{2} \mathrm{~s}\right)\right]$

ICPR: Initial Critical Power Ratio $\left(=Q_{B T} /\right.$ initial $\left.Q\right),[-]$

$M C P R$ : Minimum Critical Power Ratio, [-]

$P_{\text {ex }}$ : exit pressure, [MPa]

$Q$ : power output, [kW]

$Q_{\mathrm{BT}}$ : experimental critical power, [kW] 
$t$ : time, [s]

$t_{0}$ : time lag, [s]

$T_{\text {in }}$ : inlet temperature, $[\mathrm{K}]$

$\Delta T_{\text {in: }}$ inlet subcooling, [K]

$T_{\mathrm{w}}$ : wall temperature, [K]

$x$ : true pressure difference signal, [V]

$y$ : measured pressure difference signal, [V]

\section{Greeks:}

$\tau^{*}$, dumping time of pressure differential transmitter, [s]

$\triangle M C P R$ : the change of the MCPR in a transient process, [-]

$\Delta t$ : sampling interval, [s]

\section{Transient Experiments}

\subsection{Experimental Apparatus}

Transient tests were performed using JAEA high pressure loop. The information of the loop can be find in references (7)(8)(9). The shroud configuration, rod arrangement, rod bowing condition and axial heating profile of the rod bowing effect test set are shown in Fig.1. The basic parameter of the test section is determined based on the FLWR core design. The rod diameter and gap width between rods are $13.0 \mathrm{~mm}$ and $1.3 \mathrm{~mm}$, respectively. Total heated length is $1.26 \mathrm{~m}$. Axial power distribution is simplified to $12 \mathrm{steps}$, which simulates the axial heat flux profile in the designed FLWR core. The rods are heated indirectly by alternating-current (AC) power. As shown in Fig.1 (a), a unique power supply system is used. The 37 rods were grouped into 6 groups. Each is heated with an independent power supply kit. With this power supply system, the effect of transverse power distribution can be investigated.

Grid spacers (hexagonal honeycomb shape, $0.3 \mathrm{~mm}$ thickness and $20 \mathrm{~mm}$ height) are used to tie up the rods. Axial locations of the spacer are found in Fig.1 (b). The rod bowing condition is observed from Fig.1 (a) and (c). The central rod is bowed at the upper high-heat-flux region and to contact with the two neighboring rods at the center elevation of the upper high-heat-flux region. The rod bowing condition is carefully determined based on a sub-channel analysis result, to ensure it is the most critical one on the thermal safety ${ }^{(9)}$.

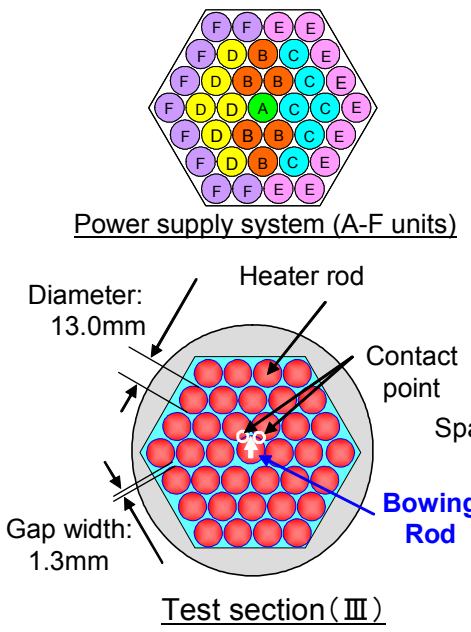

(a) Cross-sectional view

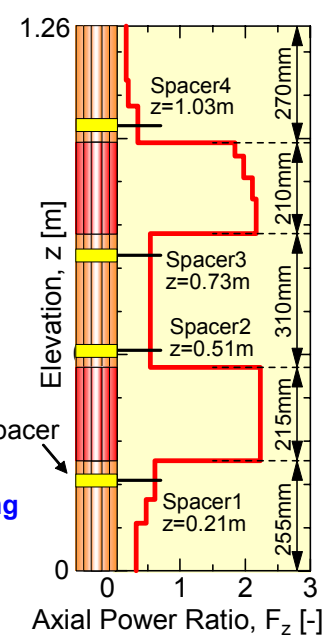

(b) Axial power distribution

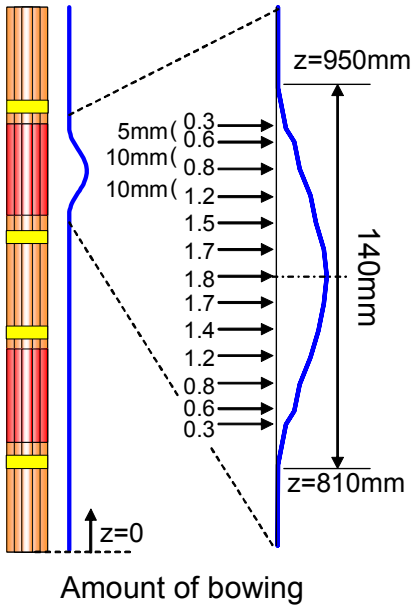

(c) Distribution of bowing

Fig. 1 Configuration of the rod bowing effect test set 
Main parameters need measuring include mass velocity $G$, exit pressure $P_{\text {ex }}$, inlet temperature $T_{\mathrm{in}}$, power output $Q$ and wall temperatures $T_{\mathrm{w}}$. In this research, mass flow is measured with a venturi tube. Heater power is calculated from the measured electric voltage and current. Mass flow and heater power under steady state are calibrated before the experiments. Their errors are within $\pm 3 \%$. Inlet water temperature is measured using high accuracy platinum resistance thermometers and is automatically controlled by a pre-heater within an error of $\pm 0.5 \mathrm{~K}$. Exit pressure of the test section is automatically controlled by a pressurizer and is measured by a high accuracy pressure sensor. For a steady exit pressure condition, the error is within $\pm 0.3 \%$. About two hundred fifty $0.5 \mathrm{~mm}$ thermocouples are buried in the surface of the heater rod to measure the wall temperature. The wall temperatures are monitored and are used to judge the occurrence of the BT.

The apparatus control system has an ability to accept beforehand programmed power increase and flow decrease input. This assures the system with the ability to perform any desired flow and power transient experiments.

\subsection{Extraction of the Transient Conditions Needed Investigation}

As we know, for the traditional BWRs and ABWRs, because they have high negative void coefficients $\left(-8 \times 10^{-4} \Delta \mathrm{K} / \mathrm{K} / \%\right.$ void for the ABWR), the severe transient processes that cause the maximum change of Minimum Critical Power Ratio $(M C P R), \triangle M C P R$, are the processes that cause the collapses of void, such as the pressure increase or the loss of feed water heating processes. However, in the FLWR, the void coefficient is decreased to $-0.5 \times$ $10^{-4} \Delta \mathrm{K} / \mathrm{K} / \%$ void, which causes the processes of the collapsing of void being no longer severe. On the other hand, a flow decrease process may become severer because the low void coefficient causes a small power decrease in the flow decrease process.

With the design strategy that except the reactor core, the FLWR plant uses the system and equipments that developed for the current ABWR, the transient processes that may be possibly met in the nominal operation of the FLWR were evaluated with $\triangle M C P \mathrm{R}$ being calculated for a natural circulation type ${ }^{(11)}$ and for a forced convection type ${ }^{(12)}$ FLWR, respectively, under a co-research carried between JAEA and the Japan Atomic Power Company (JAPC). With using the evaluation result, in this research, we extracted the severest power increase and flow decrease processes. For a natural circulation type FLWR, among the transient events (1) power increase due to a loss of feed water heating; (2) power increase due to a load rejection; (3) power increase due to an abnormal withdrawal of control rod; (4) power increases due to a failure in feed water control system; (5) flow decrease due to a total loss of feed water and (6) both power and flow decreases due to a failure in pressure control system, the severest power increase and flow decrease processes that causes the highest $\triangle \mathrm{MCPR}$ are the abnormal withdrawal of control rod and the total loss of feed water, respectively.

On the other hand, for a forced circulation type FLWR, among the transient events (1) power increase due to a loss of feed water heating; (2) power increase due to a load rejection; (3) power increase due to an abnormal withdrawal of control rod; (4) power increase due to a failure in feed water control system; (5) flow decrease due to a failure of one internal pump; (6) flow decrease due to a total loss of feed water; and (7) both the flow and power decreases due to a failure in pressure control system, the most severest power increase and flow decrease processes that causes the highest $\triangle M C P R$ are the loss of feed water heating and the failure of internal pump, respectively. The extracted severest transients are listed in Table 2. QcaseA and QcaseB correspond to the abnormal withdrawal of control rod in a natural circulation core and the loss of feed water heating in a forced circulation core, respectively. GcaseA and GcaseB correspond to the total loss of feed water in a natural circulation core and the internal pump failure in a forced circulation core, respectively. 
Table 2 The postulated severest transient processes for the FLWR

\begin{tabular}{cccc}
\hline Postulated transient processes & $\begin{array}{c}\text { Increase or } \\
\text { decrease range } \\
{[\%]}\end{array}$ & $\begin{array}{c}\text { Increase or } \\
\text { decrease rate } \\
{[\% / \text { second }]}\end{array}$ \\
\hline Power & QcaseA & +5 & +0.88 \\
increase & QcaseB & +14 & +0.22 \\
\hline Flow & GcaseA & -10 & -0.88 \\
decrease & GcaseB & -24 & -12.0 \\
\hline
\end{tabular}

Table 3 Tested transient cases

(a) "Flow decrease" test

\begin{tabular}{cccc}
\hline Parameter & Unit & Test range & Nominal Setting \\
\hline Exit pressure & $\mathrm{MPa}$ & $2,7.2$ & 7.2 \\
Initial mass velocity & $\mathrm{kg} /\left(\mathrm{m}^{2} \mathrm{~s}\right)$ & $400,600,800$ & 600 \\
Inlet subcooling & $\mathrm{K}$ & 5 & 5 \\
Radial peaking factor & - & 1.0 & 1.0 \\
$I C P R$ & - & $1.05-1.3$ & 1.3 \\
Decreasing range & $\%$ & $(-10)-(-45)$ & $(-10)^{+} /(-24)^{++}$ \\
Decreasing rate & $\% / \mathrm{s}$ & $(-1)-(-15)$ & $(-0.88)^{+} /(-12)^{++}$
\end{tabular}

(b) "Power increase" test

\begin{tabular}{cccc}
\hline Parameter & Unit & Test range & Nominal Setting \\
\hline Exit pressure & $\mathrm{MPa}$ & $2,7.2$ & 7.2 \\
Mass velocity & $\mathrm{kg} /\left(\mathrm{m}^{2} \mathrm{~s}\right)$ & $400,600,800$ & 600 \\
Inlet subcooling & $\mathrm{K}$ & 5 & 5 \\
Radial peaking factor & - & 1.0 & 1.0 \\
$I C P R$ & - & 1.05 & -1.3 \\
Increasing range & $\%$ & $(+5)-(+30)$ & $(+5)^{+} /(+14)^{++}$ \\
Increasing rate & $\% / \mathrm{s}$ & $(+0.33)-(+5)$ & $(+0.22)^{+} /(+1)^{++}$ \\
& Natural circulation core & \multicolumn{2}{c}{ Forced circulation core }
\end{tabular}

\subsection{Experimental Procedures and Conditions}

Transient tests were performed centered the postulated severest transient processes shown in Table 2. Table 3 shows the range of the tested transient cases in the present research. Besides the postulated transient processes for the FLWR core, some more severe cases were tested as well, to ascertain the transient BT characteristics in the rod bowing case. For the postulated transient cases, the tests were first performed under the condition that Initial Critical Power Ratio (ICPR) was 1.3, to check whether the BT occurs or not. To ascertain the BT characteristics, the postulated transient conditions were further tested under severe ICPR (a higher initial power) conditions. Note that here ICPR is defined as the ratio of the experimental steady critical power in the rod bowing effect case at initial mass velocity to initial power, that is

$$
I C P R=Q_{B T} \text { under steady state in the rod bowing effect case } / Q
$$

Thereby, for each transient case, experiments were conducted with $I C P R$ used as a parameter. Before the tests, dissolved gas was purged from the loop by the degassing operation. Then, mass velocity, inlet water temperature, exit pressure and heater power were controlled to specified settings. After a stable condition was confirmed being 
established under the heater power, beforehand programmed transient patterns were read by apparatus control system and then were outputted to a power thyristor or a circulation pump to control the power output and the rotation frequency of the pump, respectively. In the "flow decrease" tests, rod power, pressure, inlet subcooling were held constantly. While in the "power increase" tests, flow rate and inlet subcooling were held constantly. The pressure at the power increase tests, although was desired to be kept constantly, generally increased slightly with the increase of the power because the pressurizer failed in balancing the pressure increase in time caused by the fast power increase.

\subsection{Transient Data Processing}

It has to be notified that the data processing in transient process, compared to that in steady state, needs special attention. The time lags and dumping times caused by sensors, transmitters, A/D converters and data acquisition system need estimating. If time lags and dumping times are too large to be neglected, corrections are needed in order to get right measurements.

Response time of the $0.5 \mathrm{~mm}$ thermocouples used for wall temperature measurement is $16 \mathrm{~ms}$, according to the specifications supplied by maker. Other response times for electric voltage and current, which are used in the calculation of heater power, and for high accuracy sensor of exit pressure are considered being negligible. The response time for mass flow is determined by pressure difference transmitter. The transmitter used in the present research for the measurement of mass flow has a time lag of $0.5 \mathrm{~s}$.

Data acquisition system used in the present research is a multiplexed system. As we know, the multiplexed system causes time lags among measured channels. In the present research, the scan interval between two adjacent channels is determined by the physical characteristic of the used amplifier module. The value is $3 \mu \mathrm{s}$. In the present research, the measured turn of the parameters was set as: first the wall temperature channels, then the mass flow (pressure difference signal) channel, the power and the exit pressure channels. The time lags caused by the multiplexed system to wall temperature where BT is generally detected are within $0.1 \mathrm{~ms}$. The time lags to mass flow, power and exit pressure are within $1 \mathrm{~ms}$.

Time lags and dumping times from sensors, transmitters, A/D converters and data acquisition system are summarized in Table 4. Compared to the sampling interval of $0.1 \mathrm{~s}$ in the experiments, the time lags shown in the mass flow and pressure drop measurements are absolutely significant and need corrections.

In this research, the corrections to the pressure difference signals were performed by Eq.

(2). The correction considered only the first order derivative.

$$
x_{(t)}=y\left(t+t_{0}\right)+\left(\frac{\tau^{*}}{\Delta t}\right)\left[y\left(t+t_{0}+\Delta t\right)-y\left(t+t_{0}\right)\right]
$$

In Eq.(2), $x$ is the true pressure difference signal and $y$ is the measured one. $t_{0}$ and $\tau^{*}$ are the time lag and dumping time of a transmitter. $\Delta t$ is sampling interval. In the present experiments, it is $0.1 \mathrm{~s}$.

\section{Experimental Results}

Tested transient cases, as shown in Table. 3, covered adequately the postulated transient cases shown in Table 2. Totally 254 ("flow decrease" case, 154 runs; "power increase" case, 100 runs) runs of data were derived for the rod bowing effect test set.

For the postulated power increase and flow decrease cases shown in Table 3 , it has been confirmed from tests that when the ICPR is 1.3 , no BT occurs in the rod bowing effect test bundle. 
Table 4 Time lags and dumping times in the measurements of main parameters in transient cases

\begin{tabular}{|c|c|c|c|c|c|}
\hline \multirow[t]{2}{*}{ Response time } & \multirow[t]{2}{*}{ sensor } & \multicolumn{2}{|c|}{ transmitter } & \multirow{2}{*}{$\begin{array}{l}\text { A/D converter } \\
\text { and data } \\
\text { acquisition }\end{array}$} & \multirow{2}{*}{$\begin{array}{l}\text { Whole } \\
\text { response } \\
\text { time }\end{array}$} \\
\hline & & $\begin{array}{l}\text { Time } \\
\text { lag }\end{array}$ & $\begin{array}{c}\text { Dumping } \\
\text { time }\end{array}$ & & \\
\hline Mass flow & 0 & $0.5 \mathrm{~s}$ & $0.2 \mathrm{~s}$ & Within $1 \mathrm{~ms}$ & $0.5 \mathrm{~s}+1 \mathrm{~ms}$ \\
\hline Power & 0 & - & - & Within $1 \mathrm{~ms}$ & $1 \mathrm{~ms}$ \\
\hline Wall temperatures & $16 \mathrm{~ms}$ & - & - & Within $0.1 \mathrm{~ms}$ & $16.1 \mathrm{~ms}$ \\
\hline Pressure & 0 & 0 & $3 \mathrm{~ms}$ & Within $1 \mathrm{~ms}$ & $1 \mathrm{~ms}$ \\
\hline Total pressure drop & 0 & $0.3 \mathrm{~s}$ & $1 \mathrm{~s}$ & Within $1 \mathrm{~ms}$ & $0.3 \mathrm{~s}+1 \mathrm{~ms}$ \\
\hline
\end{tabular}

Furthermore, transient BT data have been taken under severer ICPR condition for the postulated transient cases and for some other more severe flow decrease cases. Trends of the wall temperature under transient condition are same as that in steady state ${ }^{(9)}$ : Although the temperature at the contact point is higher than that at other points, the BT occurs at downstream elevation. BT occurs at the exit elevation of the upper high-heat-flux region (MOX fuel region) axially and in the central area of the bundle transversely. This BT area is same as that in the steady state ${ }^{(9)}$ as well.

The transient critical power data taken for the postulated flow decrease and power increase transient cases under $P_{\text {ex }}=7.2 \mathrm{MPa}$ and $P_{\text {ex }}=2 \mathrm{MPa}$ are shown in Figs. 2 and 3, respectively. The transient critical powers in the postulated transient cases are generally same as the steady ones, within an error of $\pm 3 \%$.

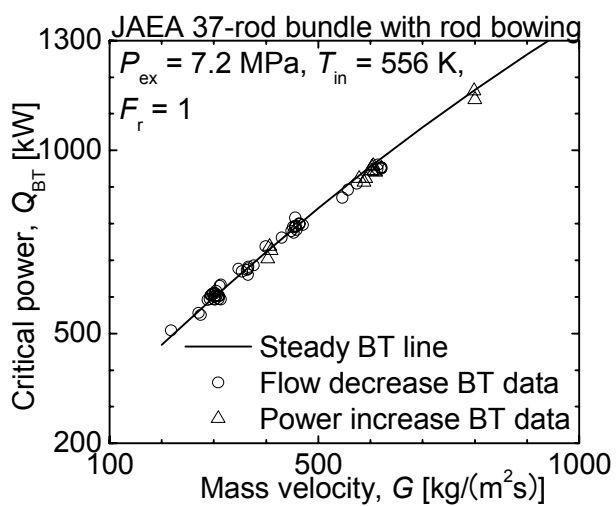

Fig. 2 Transient critical power data at $P_{\text {ex }}=7.2 \mathrm{MPa}$

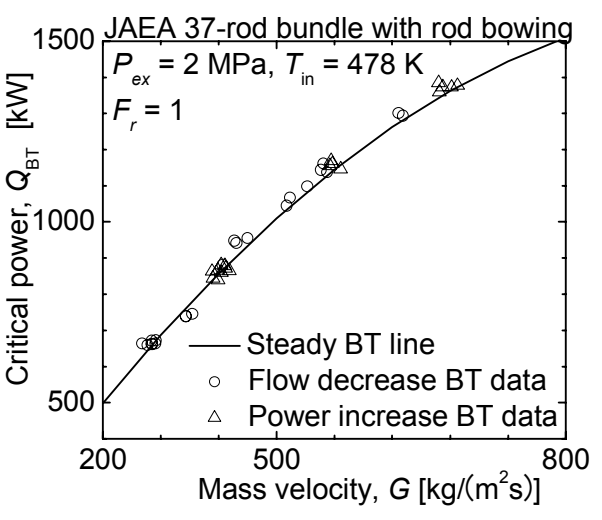

Fig. 3 Transient critical power data at $P_{\mathrm{ex}}=2 \mathrm{MPa}$

\section{Transient Test Analyses with TRAC-BF1 Code}

\subsection{Introduction to the TRAC-BF1 Code}

Transient analysis code TRAC-BF1 takes the structure of its base code TRAC-PF1, which contains full two-fluid thermal hydraulic model in both one-and three-dimensional component models. Compared to the TRAC-PF1 code, the TRAC-BF1 considers the effects of the geometric arrangement of the BWR core. Channel wall radiation heat transfer and flooding modules are added into the code. The code provides a best estimate analysis capability for analyzing not only the full range of postulated accidents in BWR systems and related facilities, but also a basic capability for the analysis of operational transients up to and including anticipated transients without scram. The code includes a module that judging the BT occurrence from a critical power correlation. The local fluid conditions used in the correlations is solved from the two fluid hydrodynamics solution in a one-dimensional 
channel component. In this research, the JAEA newest version of critical power correlation (13) for the tight-lattice rod bundles without rod bowing is revised to account for the about $10 \%$ decreasing of steady critical power in the rod bowing effect case ${ }^{(9)}$. In the JAEA newest version of critical power correlation, two kinds of liquid dryout mechanisms are considered. For the spot dryout of liquid film, which becomes dominant under comparatively high mass velocity condition, the correlation of local critical heat flux critical quality type is adopted. For the complete dryout mechanism, which becomes dominant under comparatively low mass velocity condition, the correlation is in critical quality - annular flow length type. The revised correlation is implemented in the BT judging module.

For the evaluation of pressure drop, the Martinelli - Nelson's correlation ${ }^{(14)}$, which is reported being applicable for the tight-lattice rod bundles ${ }^{(15)(16)(17)}$, is used in the code.

\subsection{Analyses results}

As showed from test results, for the postulated power increase and flow decrease transients, it has been confirmed from the tests that no BT is observed when the ICPR is 1.3. Figure 4 shows the comparisons of the tests and analyses. The code predicts the same none BT as in the tests. The predicted rod wall temperature is near to the experimental data as well.

Analyses to the postulated transient cases run under a severer ICPR with the BT occurring are also carried out. Two example results are shown in Fig.5. The TRAC-BF1 code predicts conservatively the starting time of the BT for the two transient cases. The reason is the $10 \%$ decrease of the critical power implemented in the BT judging module. The value of the $10 \%$, as can be observed from reference 9 , accounts the decreases of critical power in the rod bowing effect test somewhat excessively. The traditional quasi-steady state prediction of the transient BT has been confirmed being applicable for the postulated transient processes in the rod bowing effect case.

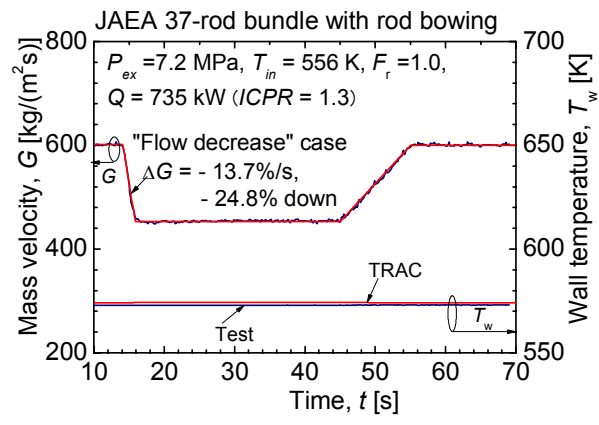

Fig.4 (a) Comparison of test and analysis for the postulated severest flow decrease case (GcaseB) at $I C P R=1.3$

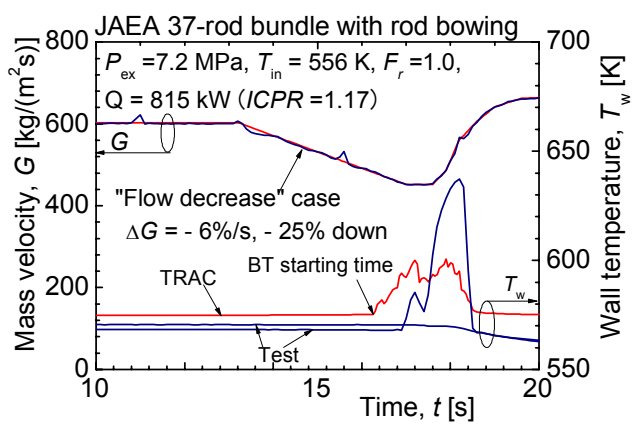

Fig.5 (a) Comparison of test and analysis for a flow decrease case with BT occurring

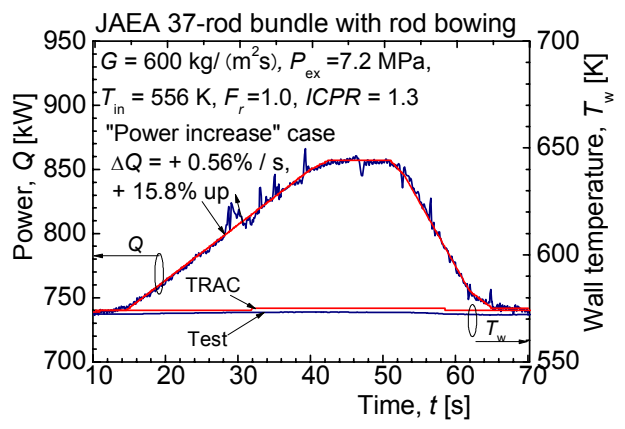

Fig.4 (b) Comparison of test and analysis for the postulated severest power increase case $(\mathrm{Q}$ caseB) at $I C P R=1.3$

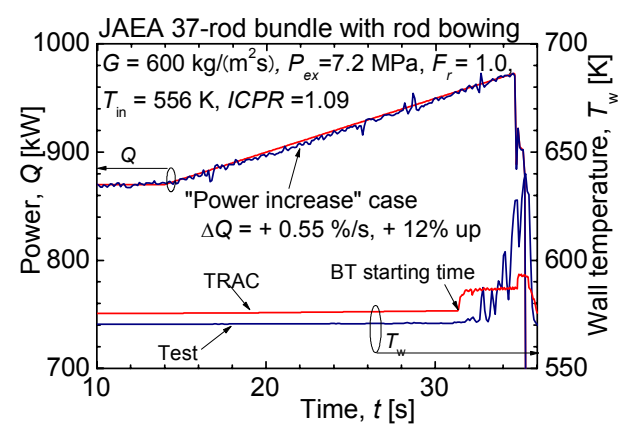

Fig.5 (b) Comparison of test and analysis for a power increase case with BT occurring 


\subsection{Discussion}

The modified TRAC-BF1 code has been confirmed being able to predict the BT starting time conservatively. However, the predicted rod temperatures in the post BT region differ from that observed in the tests and shows being non-conservative. This is because so far, no research on the heat transfer characteristics in the post BT region has been performed for the tight lattices rod bundles and the modified TRAC-BF1 code has not been tuned to predict the heat transfer in the post BT region accurately for the tight lattice rod bundles.

In Fig.5 (a), besides the wall temperature that detected the BT, another wall temperature measured from a thermocouple set on the same rod and the same axial elevation, with only facing to a different direction, is showed as well. The wall temperature keeps constant and doesn't show any jump. This states an obvious wall temperature distribution even on the same rod and on the same axial elevation, due to transverse enthalpy and mass distribution in sub-channels. How to predict the heat transfer in the post BT region conservatively is a theme to be solved in the future.

\section{Summery}

In this paper, results of critical power under transient states using a tight-lattice 37-rod bundle with rod bowing were described.

- No BT occurs when $I C P R=1.3$ in the postulated transient cases.

- The transient critical powers in the postulated transient cases are generally the same as the steady ones, within an error of $\pm 3 \%$. The wall temperature trends at BT and BT occurring area are the same as those under the steady state as well.

- The TRAC-BF1 code shows good prediction for the occurrence or the non occurrence of the BT and predicts the BT starting time conservatively. The traditional quasi-steady state prediction of the BT in transient process has been confirmed being applicable for the postulated transient processes in the tight-lattice rod bundles with rod bowing.

\section{Acknowledgments}

This paper contains results obtained within the task "Development of Fuel Assembly for Very High Burn-up Water-cooled Breeding Reactor" entrusted from the Ministry of Education, Culture, Sports, Science and Technology of Japan.

\section{References}

(1) Uchikawa S., Okubo T., Kugo T., et al., Investigation on Innovative Water Reactor for Flexible Fuel Cycle(FLWR) (1) Conceptual Design, Proceedings of GLOBAL 2005, (2005-10), Tsukuba, Japan, No. 358.

(2) Okubo T., Uchikawa S., Kugo T., et al., Investigation on Innovative Water Reactor for Flexible Fuel Cycle(FLWR) (2) Recycle Characteristics, Proceedings of GLOBAL 2005, (2005-10), Tsukuba, Japan, No. 359.

(3) Kureta M., Akimoto H., Critical Power Correlation for Axially Uniformly Heated Tight-Lattice Bundles, Nucl. Technol., Vol.143 (2003), No. 1, pp 89-100.

(4) Liu W., Kureta M. and Akimoto H., Critical Power in 7-Rod Tight Lattice Bundle, JSME Int. J., B, Vol. 47(2004), No 2, pp 299-305.

(5) Yamamoto Y., Morooka S., Arai K. et al., Critical Power Performance of the Tight-lattice Fuel Bundle, Transactions of the Atomic Energy Society of Japan, Vol. 1(2002), No. 3, pp 282-288, (in Japanese).

(6) Yamamoto Y, Hiraiwa K., Morooka S., et al., Critical Power Performance of Tight Lattice Bundle, JSME Int. J., B, Vol. 47(2004), No. 2, pp 344-350. 
(7) Kureta M., Tamai, H. Ohnuki A., et al., Critical Power Experiment with a Tight-Lattice 37-Rod Bundle, J. Nucl. Sci. Technol, Vol. 43(2006), No.2, pp 198-205.

(8) Tamai H., Kureta M., Liu W. et al., Gap Width Effect on Critical Power based on Tight-Lattice 37-Rod Bundle Experiments, J. Nucl. Sci. Technol., Vol. 44 (2007), No.1, pp.54-63.

(9) Tamai H., Liu W., Kureta M., Critical Power Test of Rod-Bowing Effect in a Tight-Lattice Bundle, 2006, Proceedings of NTHAS5: Fifth Korea-Japan Symposium on Nuclear Thermal Hydraulics and Safety (2006-11), No. E005, Jeju, Korea.

(10) Liu W., Kureta M., Tamai H., et al., Critical Power Characteristics in 37-rod Tight Lattice Bundles under Transient Conditions, J. Nucl. Sci. Technol., Vol. 44 (2007), No.9.

(11) Okubo T., Takeda R., Iwamura T., Study on Safety and Core Improvement of Reduced Moderation Water Reactor (RMWR) with High Conversion Ratio, JAERI-Research 2001-021, Japan Atomic Energy Agency (JAEA), (2001), [in Japanese].

(12) Contract research report - Study on Reduced - Moderation BWR Cores (High Conversion Ratio Core), Hitachi. LTD. (2000), [in Japanese].

(13) Liu W., Kureta M., Yoshida H., et al., An Improved Critical Power Correlation for Tight-Lattice Rod Bundles, J. Nucl. Sci. Technol., Vol.44 (2007), No.4, pp.558-571

(14) Martinelli R.C. and Nelson D. B., Prediction of Pressure Drop during Forced Circulation Boiling of Water, Trans. ASME, Vol. 70(1948), pp 695-702.

(15) Tamai H., Kureta M., Ohnuki A. et al., Pressure Drop Experiments using Tight-Lattice 37-Rod Bundles, J. Nucl. Sci. Technol., Vol.43 (2006), No.6, pp. 699-706.

(16) Morooka S., Yamamoto Y., Shirakawa K., Pressure Drop of Tight Lattice Rod Bundle, Transactions of the Atomic Energy Society of Japan, Vol. 2(2003), No. 3, pp 301-306 (in Japanese).

(17) Morooka S., Yamamoto Y., Shirakawa K., Pressure Drop of Tight Lattice Rod Bundle, Trans. JSME, B, Vol.72 (2006), No. 715, pp 701-708 